\title{
THE ANALYSIS OF THE INFLUENCE OF SOIL ON LEAKAGE IN WATER SUPPLY SYSTEMS
}

\author{
Ivana Ć́ipranić, Goran Sekulić
}

Original scientific paper Leakage modelling in water supply systems is a process, which, due to its complex nature, holds more components in itself. For the purpose of understanding the problem, the models for losses are presented, in the way they have been treated so far. Former practice has shown that it is justified to include the impact of the soil, in which the water pipes are laid, in the leakage modelling.. The reason for this is the energy loss of the water flow, which occurs between the orifice and the soil surface during the process of the water movement through the soil. This paper proposes a method for the evaluation of the soil influence, which can be implemented in existing models.

Keywords: coefficient of filtration; leakage; pressure; soil; water supply system

Analiza utjecaja tla na gubitke u vodovodnim sustavima

Izvorni znanstveni članak

Modeliranje gubitaka u vodovodnim sistemima je proces koji zbog složenosti svoje pojave, obuhvaća više komponenti. Radi razumijevanja problema prvo su dati prikazi modeliranja gubitaka, na način kako su do sada obrađivani. Neka dosadašnja istraživanja su pokazala da je opravdano da se u model gubitaka uključi i utjecaj tla u kojem su vodovodne cijevi položene, iz razloga gubitaka energije toka vode, koji se dešavaju između mjesta pukotine i površine zemljišta, usljed kretanja vode kroz zemljište. U ovom radu su date sugestije u kojim slučajevima je potrebno utjecaj tla implementirati u postojeće modele.

Ključne riječi: gubici vode; koeficijent filtracije; pritisak; tlo; vodovodni sistem

\section{Introduction}

Water supply companies have been well aware of the constant need for the rational loss rate control and therefore they aim at the reduction of that loss. Water loss reduction leads to the decrease of the costs of water supply system performance as well. In order to provide an effective way of the water loss management in water supply systems, it is of high importance to analyse thoroughly the very nature of losses, find a solution for their minimization and finally implement an operating strategy in the process of minimization. Apart from the mentioned components necessary for the effective loss rate control, it is also important to provide a hydraulic model, which describes the state of water supply systems most precisely. Mathematical models serve as a tool for modelling of water supply system behaviour and they are successfully used for the system analyses. Additionally, these models can be very helpful in the active management of the system.

A great number of the existing leakage models in the water supply systems are based on the introduction of fitting coefficients, chosen in such a way that the results of the model match the data from the leakage measuring collected in the water supply systems. In other models the classic orifice equation is used. For the purpose of developing the models, which will present the leakage and have more physical meaning, a better understanding of parameters, which control the leakage rate, is necessary [1]. Also, an effective leakage modelling demands a thorough understanding of the hydraulics of leaks through the orifices.

In the majority of models it is proposed that leaks are under the influence of the orifice. Thomas Walski et al. [1] have reached the conclusion that, in some cases, the leakage through the orifice is under the significant influence of soil, where the pipes are laid. The soil impact appears as a result of additional head losses, which occur between the orifice and the soil surface, while the water moves through the soil.

This paper presents the analysis of the influence of different soil types on the flow rate from leaks in the pipe, for various pressures in the system. More precisely, not only does it emphasize the situations in which the leakage depends on the soil head loss, but also it points to the necessity of completing the existing models with some equations, which would adequately represent the above mentioned influence.

\section{Theoretical background \\ 2.1 On water losses in water supply systems}

A detailed analysis of the problem concerning water losses in water supply systems includes the definition of the type and loss rate. For that purpose water losses are divided into main components: the background losses and the orifice losses.

The background losses refer to the total amount of water losses from all the pipelines in the network, which are, if taken separately, too small to be discovered via visual inspection or via inspection with the use of instruments based on the sound measuring. Pressure control has the greatest influence on this component of loss. The background losses, characterized as minimal losses, occur in individual orifices with the flow rate

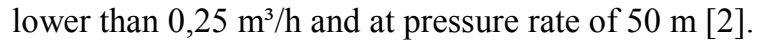

The orifice losses refer to the water loss due to the orifices found in the distribution system. The orifices can be classified as registered and unregistered. The speed necessary for detecting the orifice, and for fixing it later, influences the total amount of water losses from all the orifices; accordingly, the control of water loss duration or the leakage time minimizes the losses [2].

The effect of pressure, although being very comprehensible in theory, has only recently been received in the area of water loss control, in terms of reducing and 
maintaining a low level of loss in water distribution systems [2].

\subsection{The relationship between pressure and orifice loss}

The Law of Conservation of Energy states that the flow velocity through the pipe hole is changed into the square root function of the pressure dominating in it, according to the equation:

$v=C_{\mathrm{d}} \sqrt{2 g P}$.

Many engineers adopt the following: the loss increment in the distribution systems must be the square root function of the pressure, i.e. the losses are intensified with the pressure change. However, easily adopted assumption that the $C_{\mathrm{d}}$ value is the constant one is not always valid. For particular analyses, the coefficient of discharge can be changed in relation to the flow regime, which can be laminar, transitional or turbulent. This depends on the Reynolds number $R_{\mathrm{e}}(=v \cdot D / v)$, in which $v$ is velocity, $D$ is the diameter of the pipe, and $v$ is the kinematic viscosity that varies with temperature [3].

Another significant reason, which questions the general assumption that water losses are the square root function of the pressure, is the relationship between the leakage rate and the opening area, in accordance with the following equation:

$$
Q=v \cdot A=C_{\mathrm{d}} A \sqrt{2 g P}
$$

Concerning the longitudinal cracks on the plastic PE and PVC pipes, it is normal to expect, as it has already been proved clearly by means of numerous laboratory tests, that the area of the opening varies with the pressure change $[4,5]$. If the area changes in a linear way (the longitudinal crack is opened in one direction), then the area $(A)$ will vary with $P^{1,0}$, and the flow rate $(Q)$ with $P^{1,5}$ If the orifice is opened in two directions, longitudinal and radial, then the rule of change alters, so that the area $(A)$ varies with $P^{2,0}$, and the flow rate $(Q)$ with $P^{2,5}[3]$.

The most meaningful general equation used for simple analysis and prognosis of the relationship between leakage rate and pressure, regardless of whether a laboratory test refers to one orifice in the pipe or to the total amount of leaks in a part of distribution network [3], is:

$$
\frac{Q_{1}}{Q_{0}}=\left(\frac{P_{1}}{P_{0}}\right)^{N}
$$

where $P_{0}$ and $Q_{0}$ represent the initial pressure and leak flow rate in the waterworks, $P_{1}$ and $Q_{1}$ are the coefficients of corrected pressure and leak flow rate, while the exponent $N$ depends on the prevailing orifice type and on the pipe materials - rigid or flexible.

Analyses of over 100 field tests on sections of distribution systems in Japan and district metered areas in Australia, Brazil, Canada, Malaysia, New Zealand, UK and the USA have confirmed that the $\mathrm{N}$ exponent typically ranges from 0,5 to 1,5 but may occasionally reach the value of 2,5 . The Japanese use a weighted average exponent value of 1,15 . The weighted average of substantial numbers of tests from the UK is also close to 1,0 (linear). Tests on systems where all detectable leaks have been repaired or temporarily shut off, leaving only background (undetectable) leakage, tend to produce high $N$ exponents close to 1,5 [6]. Researchers have suggested that the exponent $N$ is 0,5 for fixed area. "If the leak behaves as an orifice, the exponent $N$ is $0,5 "$. [1]

The majority of mathematical models accepted Eq. (3) as a base for leakage modelling, adopting different values of the exponent $\mathrm{N}$.

\subsection{Present software packages for water supply system modelling}

Existing software packages normally solve node-level modelling of the relationship between the consumption and leakage rate, in some ideal working conditions of the water supply system, providing that the consumption value is given, that pressure varies and the leaks are proportionally included into consumption. For example, the software package "Wesnet" (also called "InfoWorks") uses the option "Pressure - Related Demand" to solve this. Its main idea is that the given consumption and leaks are related to nominal working pressure (if the local pressure is different, the consumption and leak rates are changed) [7].

Similar possibilities have been offered by the software package "Epanet" with its function, so-called "Emitters", by means of which the leakage rate is shown in the consumption node. This option introduces physically a fictitious pipe between the junction and a fictitious reservoir. The level at the fictitious reservoir is the elevation of the junction. The calculated flow through the fictitious pipe is the flow defined as the loss [8].

In software "Aquanet" the losses are included into the attributes of the pipe joints, where the leak rate is set in advance at $\mathrm{m}^{3} / \mathrm{km}$ with pressure of $105 \mathrm{~Pa}$. By means of using the already stated leakage rates in the pipe opening with different pressures, the rate would be recomputed for real pressures in the network [9]. "Pressure Related Discharge Node" is another option within the program, which enables the discharge monitoring in a specific node of the network, which corresponds with the pressure change in the same node [10]. This option can be used for the pipeline damage simulation, when the leakage is very significant and easily noticeable.

Additionally, it should be taken into consideration that water consumption is also pressure dependent [11].

\subsection{The leakage representation in the water supply systems with "improved model"}

Equations associated with the leak have been added to the models with standard equations for the water supply system. This offers an "improved model" which enables a sustainable pressure control and leakage analysis. The estimated total water loss in the network is distributed at nodes, in proportion with the consumption in nodes. Accordingly, equation for each node is [12]: 


$$
q_{l i}(t)=a_{i} \cdot P_{i}^{N}(t)
$$

where: $q_{l i}(t)$ is the leakage of node $i$ at time $t ; P_{i}(t)$ is pressure of node $i$ at time $t ; N$ is the leakage exponent; $a_{i}$ is the leakage factor of node $i, a_{i}=\beta \cdot d_{i}(12: 00) ; \beta$ is a constant; $d_{i}(t)$ is the node demand.

The total leakage at 12:00 appears as a result of the summation of the total leakage of all nodes:

$$
Q_{l(12: 00)}=\sum_{i} \beta \cdot d_{i(12: 00)} \cdot P_{i(12: 00)}^{1,1},
$$

Here the leakage exponent $N$ is 1,1 as an average value of that coefficient for networks in which the background losses appear as well as the orifice leakage. In order to estimate the factor $\beta$, which is a constant through time, the chosen time is $12: 00$ p.m.

The coefficient $\beta$ is calculated by means of equation:

$$
\beta=\frac{Q_{l(12: 00)}}{\sum_{i} d_{i(12: 00)} \cdot P_{i(12: 00)}^{1,1}},
$$

and the leakage factor is calculated by means of equation:

$a_{i}=\beta \cdot d_{i(12: 00)}$

The real water consumption, consumption without losses, $d_{i}(t)$, is calculated for each node by subtracting the loss from the total demand, for each point of time $t$ [13]:

$$
\overline{d_{i}}(t)=d_{i}(t)-a_{i} \cdot P^{1,1}{ }_{i}(t)
$$

Improved models represent the leakage in the water supply systems in the most suitable way. However, like all the other models, improved models have certain disadvantages. In spite of great progress made in the area of leakage modelling, so many problems have remained and they require further work and research.

\subsection{Disadvantages of former models}

Not all previously adopted assumptions within some models are always valid for the operative control of "realworld" water supply systems.

One of the disadvantages of the models is neglecting the soil head loss. As it has already been stated, in the large number of cases the losses are modelled under the assumption that the loss rate is controlled by the size of an orifice and pressure, Eq. (2). But, in larger leaks, the water will move through the soil and reach the surface area. In that case, the outside piezometric level will actually become constant. The drawn conclusion is the following: in the case of smaller leaks, additional head losses will occur between the leak and the soil surface, while the water moves through the soil, Figure 1, [1].

It is also possible that the soil head losses are larger than the orifice head losses. Neglecting this fact in the process of modelling of the system performance will result in a model which does not match the "real-world" water supply systems.

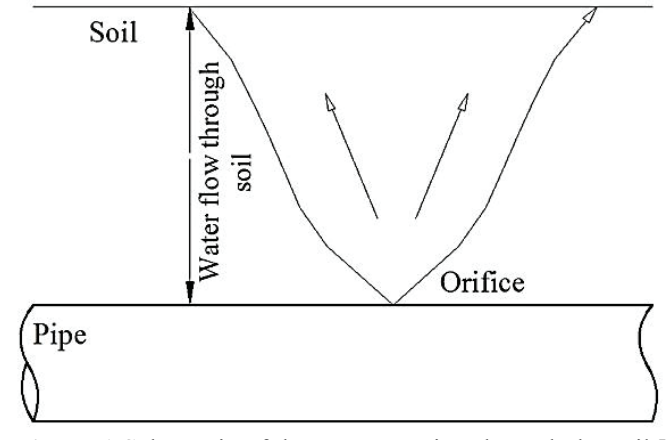

Figure 1 Schematic of the water moving through the soil [1]

\section{Former analyses of the soil influence on losses}

After careful literature analysis, we concluded that Thomas Walski et al. [1] provided the most thorough account of the soil influence on losses in water supply systems. In this section we will give a concise outline of their experiment, the definition of the OS number and the acquired results.

\subsection{The experiment description}

Fig. 2 represents the schematic of the experiment apparatus.

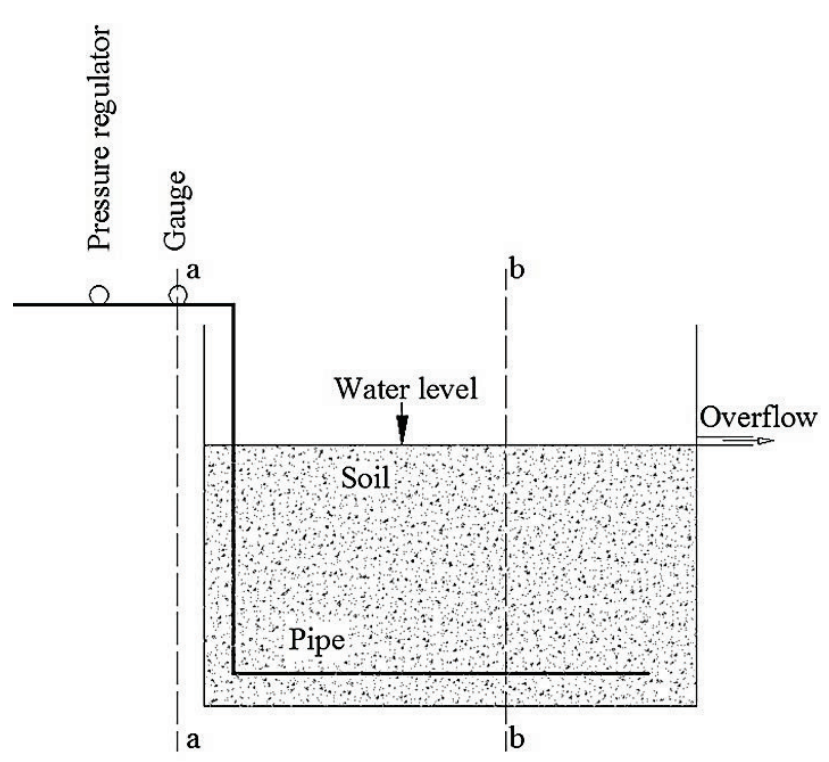

Figure 2 Schematic of the experiment apparatus [1]

The apparatus consists of a pipe with drilled holes, pressure regulator and pressure gauge, a cylinder filled with sand, in which the pipe is laid, and an overflowing pipe. The authors considered two situations in order to determine the difference between the leakage controlled by the soil head loss and the leakage controlled by the orifice head loss. In the first case, referred to as "the short apparatus", there was a cylinder $48 \mathrm{~cm}$ tall, with an inside diameter of $38 \mathrm{~mm}$ and an overflowing pipe of $43 \mathrm{~cm}$. In the second case, known as "the tall apparatus", there was a cylinder $157 \mathrm{~cm}$ tall, because of larger head losses caused by the water movement through the material found in the cylinder. An inside diameter was of 10,2 cm. As far as this cylinder is concerned, the flow velocity was great due to the smaller cross-section area. The pipe with holes was laid at the bottom of the cylinder. The experiments 
were conducted with various orifice sizes, ranging from $1,067 \mathrm{~mm}$ to $9,35 \mathrm{~mm}$. The inlet pressure was controlled with a pressure regulator. The cylinders were filled with sand for one reason: sand is resistant to compression and it can be used for more than just one test, displaying no significant change of the hydraulic conductivity. The bottom of the cylinder, i.e. the space around the pipe, was filled with gravel for the purpose of easier water flow.

During the experiment the pressure gauge was used for measuring the inlet pressure. The discharge rate was measured by collecting the water that flowed through the overflow at specific period of time. The flow rates were measured for pressures of 69, 103, 137, 172 and $206 \mathrm{kPa}$, for all orifice sizes. In order to calculate the discharge coefficient for the leak through orifices, $\mathrm{Cd}$, the flow rate for all five pressures in the pipe free of sand was measured (the free flow). The values of the measured discharge coefficient ranged from 0,71 to 0,76 . The experiments were performed using various orifice sizes, various flows, pressures and soil velocities in both cases, in the short apparatus and in the tall one as well.

\subsection{The OS number definition}

On the basis of schematic of the described experiment, by means of the energy equation which links the pressure and flow for the cross-cuts a and b, Fig. 2, it is possible to present the orifice head losses and the soil head losses with a common model.

The energy equation for the case in Fig. 2 is shown:

$z_{\mathrm{a}}+\frac{P_{\mathrm{a}}}{\gamma}+\frac{v_{\mathrm{a}}^{2}}{2 g}=z_{\mathrm{b}}+\frac{P_{\mathrm{b}}}{\gamma}+\frac{v_{\mathrm{b}}^{2}}{2 g}+h_{\mathrm{p}}+h_{\mathrm{o}}+h_{\mathrm{s}}$,

where: $h_{\mathrm{p}}$ is the head loss in the pipe; $h_{\mathrm{o}}$ is the orifice head loss; $h_{\mathrm{s}}$ is the head loss in soil.

Providing the head losses in the pipe are insignificantly small in relation to other losses (because the length of the pipe is short), and that atmospheric pressure is at the water surface $\left(P_{\mathrm{b}} / \gamma=0\right)$, the energy equation will be presented in the following way:

$z_{\mathrm{a}}+\frac{P_{a}}{\gamma}-z_{\mathrm{b}}=h_{\mathrm{o}}+h_{\mathrm{s}}$

Darcy's law will be applied for the water movement through the soil:

$$
Q=K \cdot A \cdot\left(\frac{h_{\mathrm{s}}}{L}\right)
$$

where: $K$ is the filtration coefficient; $A$ is the cross-cut area of soil; $h_{\mathrm{s}}$ is the head loss through the soil; $L$ is the length of the flow.

Accordingly, the equation for the soil head loss is:

$$
h_{\mathrm{s}}=\frac{Q \cdot L}{K \cdot A}
$$

The orifice flow can be calculated by means of the equation:
$Q=C_{\mathrm{d}} A_{\mathrm{o}} \sqrt{2 g h_{\mathrm{o}}}$,

where: $C_{\mathrm{d}}$ is the discharge coefficient; $A_{\mathrm{o}}$ is the area of the orifice cross-cut; $h_{\mathrm{o}}$ is the orifice head loss.

The previous equation provides the orifice head loss:

$h_{\mathrm{o}}=\frac{1}{2 g}\left(\frac{Q}{C_{\mathrm{d}} \cdot A_{\mathrm{o}}}\right)^{2}$.

The combination of equations for $h_{\mathrm{o}}$ and $h_{\mathrm{s}}$ with the energy equation leads to:

$z_{\mathrm{a}}+\frac{P_{\mathrm{a}}}{\gamma}-z_{\mathrm{b}}=\frac{1}{2 g}\left(\frac{Q}{C_{\mathrm{d}} \cdot A_{\mathrm{o}}}\right)^{2}+\frac{Q \cdot L}{K \cdot A}$,

that is:

$H_{\mathrm{c}}=\frac{1}{2 g}\left(\frac{Q}{C_{\mathrm{d}} \cdot A_{\mathrm{o}}}\right)^{2}+\frac{Q \cdot L}{K \cdot A}$.

Division of this equation by other addend provides the following:

$\frac{H_{\mathrm{c}} \cdot K \cdot A}{Q \cdot L}=\frac{K \cdot A \cdot Q}{2 g \cdot L}\left(\frac{1}{C_{\mathrm{d}} \cdot A_{\mathrm{o}}}\right)^{2}+1$.

The first addend refers to the relationship between the orifice head losses and soil head losses. That number is called the $O S$ number (Orifice / Soil Number) [1]:

$O S=\frac{K \cdot A \cdot Q}{2 g \cdot L}\left(\frac{1}{C_{\mathrm{d}} \cdot A_{\mathrm{o}}}\right)^{2}=\frac{h_{\mathrm{o}}}{h_{\mathrm{s}}}$.

The $O S$ number is a non-dimensional one, indicating the type of flow realized in some situation. This means that with the $O S$ number it can be determined whether the soil head losses or orifice head losses are dominant in a particular case.

\subsection{The results of the experiment}

The ratio of the exponent $\mathrm{N}$ from Eq. (3) and the $O S$ number is derived from the results of the experiment, Fig. 3.

When the $O S$ number is 1 , the soil head losses and orifice head losses are equal. When the $O S$ number is smaller than 1, the soil head losses are dominant and if it is larger than 10, the orifice head losses are dominant.

As shown in the diagram in Fig. 3, high value of the $O S$ number matches the exponent $N$ of 0,5 thus pointing to the fact that leakage depends on the orifice head loss. In this case the soil head loss is insignificant. When the $O S$ number is near 1, the leakage through the orifice is the function of the soil head loss and of the orifice head loss as well. Low values of the $O S$ number $\left(h_{\mathrm{s}}>h_{\mathrm{o}}\right)$ indicate that the leakage through the orifice is under the influence of the soil head loss. The transition range from one 
controlled condition to another is very small, and it occurs when the $O S$ number is near 1 .



Figure 3 Diagram of the relationship between the exponent $N$ and the OS number [1]

The presented analyses indicate that the factors which control the leakage can be predicted on the basis of values of the $O S$ number, i.e. values of the $O S$ number help us determine whether the leakage is in relation to the orifice flow or to the water movement through neighbouring soil.

The test demonstrates the following: relatively high flow rate is necessary so that the leakage would be controlled by the soil head loss, which suggests low value of the $O S$ number. This means that in the majority of environments soil probably will not influence the leakage considerably. Obviously, this requires a high fluid velocity.
In the real-world systems, the $O S$ number is usually higher than 1,0 which indicates that the leakage losses are more dominant than the soil head losses.

If the $O S$ number is $<1$, a large leak would need to happen in soil with low conductivity in order to conclude that the orifice leakage is controlled by the soil head loss.

\section{The analysis of the influence of the soil type on the values of the $O S$ number}

We calculated the values of the $O S$ number (on the basis of Eq. (18)) for different filtration coefficients of neighbouring soil, orifice sizes in the pipes and pressure in the system. The cross-sectioned area, through which we calculated the flow, was adopted and it amounts to $A=$ $1 \mathrm{~m}^{2}$, due to the simplification of calculation.

The diagram in Fig. 4 demonstrates that the leakage is controlled by the soil head loss (if the $O S$ number is $<0,1$ ) if there is a higher flow rate (larger orifice diameter) and if the filtration coefficient of neighbouring soil is smaller. Also, we conclude that the influence, under the given parameters - pressure in the system is $1,5 \times 10^{5} \mathrm{~Pa}$, is greater than it is for the pressure of $3 \times 10^{5} \mathrm{~Pa}$.

The framed field in the diagram is a schematic of the system state, for which it would be necessary to model the soil head loss, and thus complete the hydraulic model of the entire system. Geological compositions of the soil types, which match the low values of the leakage coefficients, are: clays, silts, silt sands, etc.

From everything above mentioned we draw the conclusion that if the $O S$ number is $<0,1$, the model of the losses in the system, for already specified parameters, can be completed by introducing the Eq. (11).

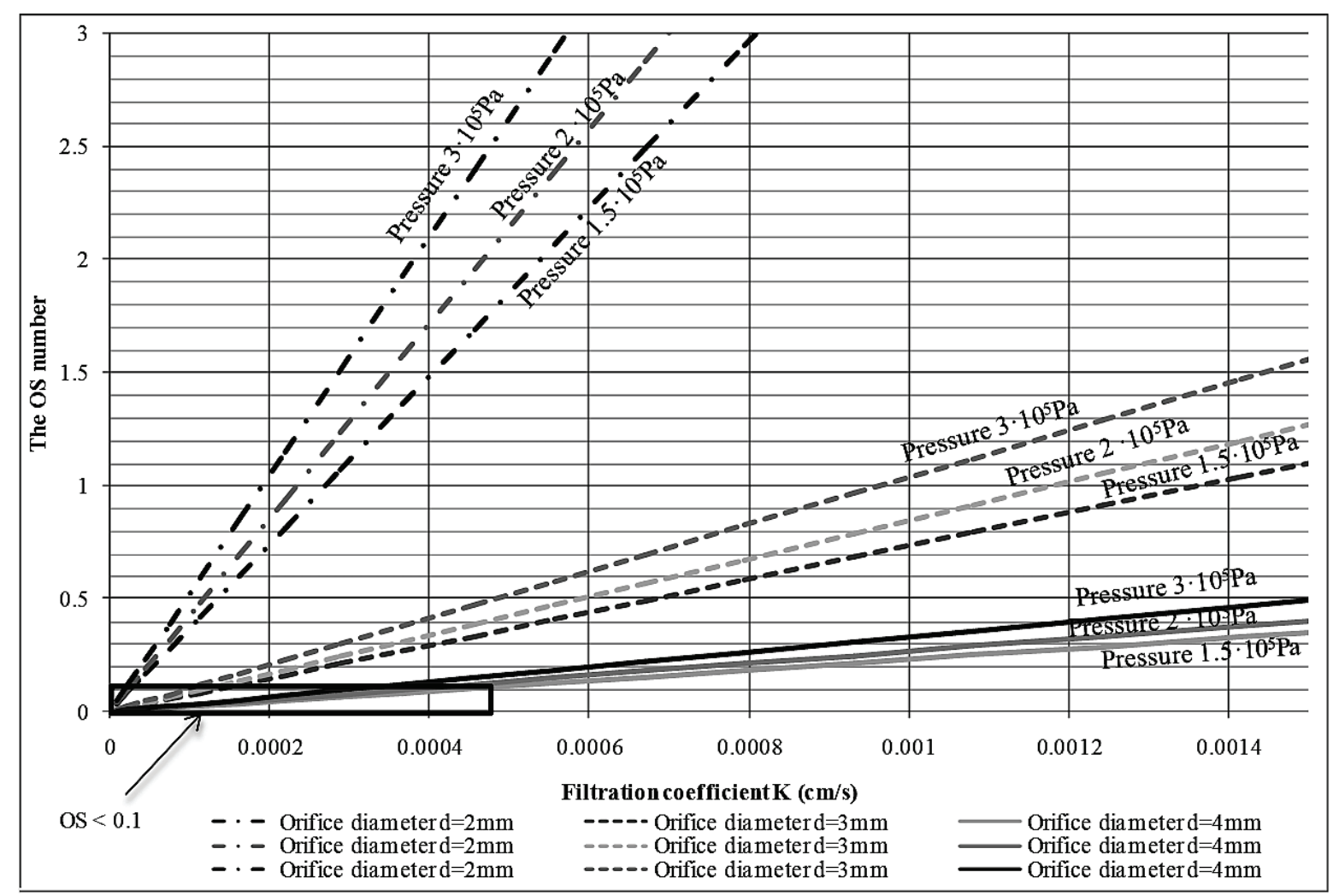

Figure 4 The dependence of the $O S$ number upon the filtration coefficient of the neighbouring soil and the orifice size in the pipes, for varying pressure in the system 


\section{Conclusion}

All existing leakage models deal with the modelling of nodal consumption-leakage relation. Improved models enable a sustainable control of pressure and leakage analysis. Although these models present the losses in water supply systems most accurately, yet they have some disadvantages. One of these is neglecting the water flow through the soil. It has been shown that the influence of the water moving through the soil cannot be neglected, especially if the soil with low values of the filtration coefficient is concerned. The value of the $O S$ number implies when it is necessary to complete the leakage model with the equations referring to the water moving through the neighbouring soil.

The recommendation suggested in this paper refers to the necessity of including the influence of the water moving through the soil into further dealing with leakage modelling in water supply systems. This would be of high importance especially within those water systems which are ruinous and which are found in the soil with low values of the filtration coefficient (clay, silt, silt sand, etc.).

\section{References}

[1] Walski, T.; Bezts, W.; Posluszny, E.; Weir, M.; Whitman, B. Modeling Leakage Reduction through Pressure Control. // American Water Works Asociaton. 98, 4(2006), pp. 147155

[2] Ivetić, M.; Prodanović, D.; Janković, Lj. Osnovne zone bilansiranja - Upustvo, Beograd, 2008.

[3] Lambert, A. What Do We Know About Pressure: Leakage Relationships in Distribution Systems? // Proceedings of IWAConference "System Approach to Leakage Control and Water Distribution Systems Management", Brno, 2000.

[4] Ashcroft, A.; Taylor, D. The Ups and Downs of Flow and Pressure. // Surveyor. (1983), pp. 16-18.

[5] Khadam, M. A.; Shammas, N. Kh.; Al-Feraiheedi, Y. Water Losses from Municipal Utilities and their Impacts. // Water International. 16, (1991), pp. 254-261. DOl: 10.1080/02508069108686121

[6] Thornton, J.; Lambert, A. Progress in Practical Prediction of Pressure: Leakage, Pressure: Burst Frequency and Pressure: Consumption Relationships. // Proceedings of IWA Special Conference "Leakage 2005", Halifax, Nova Scotia,Canada, September, 2005.

[7] http://www.innovyze.com/, 2014.

[8] Rossman, A. Epanet 2 User's Manual, http://www.epa.gov/, 2000 .

[9] http://www.finite-tech.com/, 2014.

[10] Sekulić, G.; Ćipranić, I. Problematika modeliranja gubitaka u vodovodnim sistemima. // Voda i sanitarna tehnika. 2, (2007), pp. 29-36

[11] Babić, B.; Đukić, A.; Stanić, M. Managing water pressure for water savings in developing countries. // Water SA. 40, 2(2014). DOI: 10.4314/wsa.v40i2.4

[12] Abdel Meguid, H. S. Pressure, Leakage and Energy Management in Water Distribution Systems, DE Montfort University, Leicester, 2011.

[13] Brown, K. Modeling Leakage in Water Distribution Systems, The Florida State University, 2007.

[14] Guo, S.; Zhang, T.; Shao, W.; Zhu, D. Z.; Duan, Y. Twodimensional pipe leakage through a line crack in water distribution systems. // Journal of Zhejiang University-
SCIENCE A (Applied Physics \& Engineering) ISSN 1673565X (Print); ISSN 1862-1775 (Online), 2013.

[15] Ferrante, M. Experimental investigation of the effects of pipe material on the leak head-discharge relationship. // Journal of Hydraulic Engineering. 138, 8(2012), pp. 736743. DOI: 10.1061/(ASCE)HY.1943-7900.0000578

[16] Guo, S.; Zhang, T.; Zhang, Y.; Zhu, D. Z. An approximate solution for two-dimensional groundwater infiltration in sewer systems. // Water Science and Technology. 67, 2(2012), pp. 347-352. DOI: 10.2166/wst.2012.568

\section{Authors' addresses}

\section{Ivana Ćipranić, assistent}

Faculty of Civil Engineering, University of Montenegro Cetinjski put bb, 81000 Podgorica, Montenegro

E-mail: ivanacipranic@yahoo.com

PhD Goran Sekulić, profesor

Faculty of Civil Engineering, University of Montenegro Cetinjski put bb, 81000 Podgorica, Montenegro

E-mail: sgoran2000@gmail.com 